\title{
RIO DE JANEIRO: CENÁRIO TURÍSTICO CARIOCA EM TEMPOS DE PANDEMIA
}

\author{
RIO DE JANEIRO: CARIOCA TOURIST SCENARIO IN PANDEMIC TIMES
}

RIO DE JANEIRO: ESCENARIO TURÍSTICO CARIOCA EN TIEMPOS DE PANDEMIA

\begin{abstract}
RESUMO
Este artigo analisa os impactos da pandemia da Covid-19 nos fluxos turísticos e na economia do turismo carioca e procura compreender seus significados para o conjunto da sociedade, considerando a complexa engrenagem que caracteriza o fenômeno do turismo. O recorte espacial recai no município do Rio de Janeiro, para o qual o turismo tem sua importância revelada não apenas por sua classificação na categoria "A" no Mapa do Turismo Brasileiro, mas, sobretudo, por congregar importantes produtos e fluxos em escala nacional e internacional. Reflete, portanto, parte do clima de tensões e incertezas que o panorama pandêmico provoca no turismo brasileiro. A análise, de caráter qualitativo, é complementada por dados quantitativos relacionados aos fluxos turísticos e aos impactos econômicos, análise documental e entrevistas semiestruturadas, tendo como recorte temporal os anos de 2019 e 2020. Os achados revelam diversos conflitos na condução da crise sanitária, com sérios impactos no turismo. A discussão dividese em duas partes: (i) a contextualização do município do Rio de Janeiro e sua trajetória territorial turística e econômica nas três últimas décadas até a contemporaneidade; (ii) a análise dos impactos da crise sanitária no turismo carioca. Destaca-se que o Rio de Janeiro, como destino turístico, sofreu impactos econômicos significativos, devido ao fechamento de empresas, cancelamento de eventos e interrupção de fluxos devido à restrição instituída por decretos. Na esfera municipal, o Estado agiu para amenizar os impactos, enquanto empresas reinventaram serviços e operações, o que pode oferecer informações sobre a nova configuração do destino turístico.
\end{abstract}

Palavras-chave: Pandemia. Covid-19. Turismo. Rio de Janeiro-RJ.

\section{ABSTRACT}

This article analyzes the impact of the Covid-19 pandemic on tourist flows and the on carioca tourism economy and seeks to understand its meanings for society, considering the complex mechanism that characterizes the phenomenon of tourism. The spatial cutout delimits the Rio de Janeiro municipality, for which tourism has its importance revealed not only by its highest classification on the Brazilian Tourism Map, but also for bringing together important products and flows on a national and international scale, in order to sample the climate of tensions and uncertainties that the pandemic panorama has provided in Brazilian tourism. The qualitative analysis is complemented by quantitative data, documentary analysis and semi-structured interviews, cutting out the years 2019 and 2020. The findings have pointed out several conflicts in the conduction of the health crisis, with serious impacts on tourism. The discussion is divided into two parts: (i) the background of Rio de Janeiro municipality and its territorial turistic trajectory and economic in the last three decades until contemporary, when we experience a pandemic with an intense impact on tourism and; (ii) the analysis of the impacts of the health crisis on tourism in Rio. It should be noted that Rio de Janeiro, as a tourist destination, suffered impacts due to the closing of companies, cancellation of events and interruption of flows due to the restriction instituted by decrees. In the municipal sphere, the State acted to mitigate the impacts, while the companies innovated on services and operations, which can point out about the new configuration of the touristic destination.

Keywords: Pandemic. Covid-19. Tourism. Rio de Janeiro-RJ.

\section{RESUMEN}

Este artículo analiza los impactos en los flujos turísticos y en la economía del turismo en Río de Janeiro en el contexto de la pandemia de Covid-19, y busca

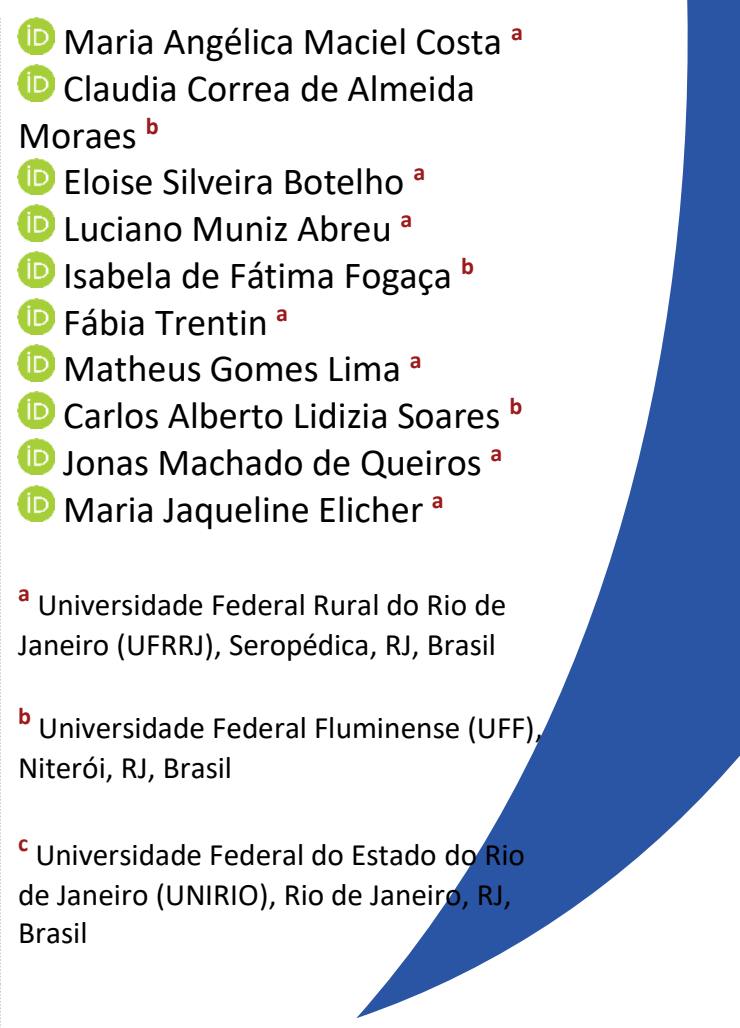

DOI: 10.12957/geouerj.2021.61340

Correpondência: mangelicamc@ufrrj.br

Recebido em: 15 mar. 2021

Aceito em: 19 jun. 2021 
comprender su significado para la sociedad, considerando la complejidad que caracteriza el fenómeno turístico. Para este estudio se eligió el municipio de Río de Janeiro, para el cual el turismo tiene su importancia revelada por su clasificación máxima en el Mapa do Turismo Brasileiro, y también por reunir productos y flujos importantes a nivel nacional e internacional, reflejando parte del clima de tensiones e incertidumbres que el panorama pandémico provoca en el turismo brasileño. El análisis es cualitativo y utilizó documentos y entrevistas semiestructuradas que fueron complementados con datos cuantitativos de los flujos turísticos y de los impactos económicos en los años 2019 y 2020. Los resultados, revelan conflictos en la conducción de la crisis de salud, con graves impactos en el turismo. La discusión se divide en dos partes: (i) la contextualización del municipio de Río de Janeiro y su trayectoria territorial turística y económica en las últimas tres décadas, en la cual se vive una pandemia con un fuerte impacto en el turismo en 2020; y (ii) análisis de los impactos de la crisis de salud en el turismo en Río. Es de destacar que Río de Janeiro, como destino turístico, sufrió impactos y, por cierre de empresas, cancelación de eventos e interrupción de flujos por la restricción instituida por decretos. A nivel municipal, el Estado actuó para mitigar los impactos, mientras las empresas reinventaron servicios y operaciones, que pueden ofrecer información sobre la nueva configuración del destino turístico.

Palabras-clave: Pandemia. Covid-19. Turismo. Rio de Janeiro-RJ. 


\section{INTRODUÇÃO}

O encontro virtual "Rio de Mãos Dadas: Juntos na Retomada da Economia", realizado no dia 25 de janeiro de 2021, reuniu as principais autoridades fluminenses e evidenciou o tom otimista para a retomada do turismo no estado do Rio de Janeiro (RJ). Nesse evento, o governador em exercício, Cláudio Castro, argumentou sobre a aposta no chamado "turismo de proximidade"(BARRETO, 2007), e afirmou que o Estado encontrava-se preparado para receber o turista, tanto no quesito segurança pública, quanto em relação ao atendimento hospitalar - mesmo reconhecendo a existência de uma fila de espera para vagas em hospitais na rede pública estadual. O recém-empossado prefeito da capital fluminense, Eduardo Paes, presente no evento, seguiu o mesmo tom de otimismo (SESC, SENAI, 2021).

Desde o mês de março de 2020, quando a Organização Mundial da Saúde notificou os países-membros sobre a pandemia de Covid-19 e sugeriu o isolamento social como uma das principais medidas para combatêla, o turismo foi afetado em diferentes escalas e dimensões. Por ser um sistema aberto, o deslocamento geográfico, a interação social e a hospitalidade são inevitáveis (HALL; SCOTT; GÖSSLING, 2020).

Na capital fluminense, o turismo ocupa papel econômico significativo. Em 2018, o setor de Serviços representava cerca de $68 \%$ do Produto Interno Bruto (PIB) municipal, de acordo com o Instituto Brasileiro de Geografia e Estatística (IBGE, 2018). Por sua vez, o PIB direto das atividades de viagem e turismo representava cerca de 3,7\%, movimentando, aproximadamente, US\$ 4,6 bilhões, e respondendo por cerca de 3,1\% dos postos de trabalho no município. O percentual de participação na economia carioca é equivalente à participação do turismo na economia de outros importantes destinos turísticos internacionais como Nova Iorque $(3,5 \%)$, São Francisco $(3,1 \%)$, Madri $(2,8 \%)$ e Berlin $(3,5 \%)$, por exemplo, segundo o World Travel \& Tourism Council - WTTC (WTTC, 2019) ${ }^{1}$. Assim, o município do Rio de Janeiro é um importante ícone do setor de turismo, não só regional, mas nacional, sendo classificado como " $A$ " na categorização do Mapa do Turismo Brasileiro.

O setor foi fortemente impactado pelos desdobramentos da pandemia de Covid-19, nos mais variados aspectos, sobretudo no que tange às questões econômicas. Cálculos feitos pelo Instituto Brasileiro de Economia da Fundação Getúlio Vargas (FGV) apontam que o município do Rio de Janeiro, por exemplo, perdeu cerca de $R \$ 5,5$ bilhões em 2021 com o cancelamento do carnaval, o que equivale a 1,4\% do PIB carioca (FGV, 2021). Diante dessa conjuntura, no âmbito do Grupo de Pesquisa "Turismo em tempos de pandemia: uma análise multi e trans-escalar", o presente artigo visa analisar o impacto da pandemia de Covid-19 nos fluxos

\footnotetext{
${ }^{1}$ Muito embora o volume de recursos movimentados pelo PIB nestas localidades seja bem superior ao da capital fluminense, perfazendo US\$ 26 bilhões, US\$5,2 bilhões, US\$ 7,8 bilhões e US\$ 7 bilhões, respectivamente.
} 
turísticos e nos resultados na economia do turismo carioca, a fim de desvelar seus significados para o conjunto da sociedade, considerando a complexa engrenagem que caracteriza o fenômeno do turismo.

Optou-se pela pesquisa de caráter qualitativo, tendo como recorte geográfico o município do Rio de Janeiro com o olhar sob as ações governamentais e resultados dos efeitos da pandemia nas questões relativas aos empregos, impostos, eventos, fluxos turísticos, abertura e fechamento de empresas, pela importância que estes indicadores representam para o setor.

A primeira fase da pesquisa baseou-se na revisão bibliográfica sobre o contexto do município do Rio de Janeiro e sua trajetória territorial no âmbito do turismo e economia referente às três últimas décadas até a contemporaneidade. Ainda, realizou-se coleta de dados quantitativos que auxiliassem na compreensão dos impactos econômicos e sociais da pandemia de Covid-19 na capital fluminense, referentes ao turismo. Utilizaram-se dados dos anos de 2019 e 2020 relacionados às Atividades Características do Turismo (ACT), finanças públicas, arrecadação de Impostos sobre Circulação de Mercadorias e Serviços (ICMS) e Imposto sobre Serviços (ISS), Receitas e Despesas. Em relação ao setor privado, foram abordados dados a respeito de falências, admissões, demissões, taxa de ocupação, dentre outros, bem como foram analisados dados sobre fluxos de turistas nos atrativos, eventos e modais de transportes no município. Quanto à atuação do governo municipal, foram levantadas informações sobre as principais ações tomadas relacionadas ao setor de turismo, tanto no sentido de conter o avanço da pandemia quanto de minimizar os seus efeitos sobre o setor.

Numa segunda etapa, foram realizadas entrevistas semiestruturadas (gravadas em plataforma digital Meet), com representantes da Secretaria Especial de Turismo e Legado Olímpico (SETURLEO) da prefeitura municipal do Rio de Janeiro, da Associação Brasileira de Empresas de Eventos (ABEOC) e da Federação de Convention \& Visitors Bureaux do Estado do Rio de Janeiro (FC\&VB-RJ). Esses interlocutores foram selecionados devido à capacidade de articulação e influência nas políticas privadas e públicas para o setor de turismo.

Dessa forma, este artigo divide-se, em duas partes, além desta introdução e das considerações finais. Na primeira, é apresentada a contextualização do município do Rio de Janeiro como destino turístico, discorrendo sobre o modelo adotado de planejamento estratégico de cidades e as crises da contemporaneidade, em contexto de uma pandemia, ainda em curso, que impacta severamente o turismo. Na segunda parte, analisam-se os impactos da pandemia nos mais diversos aspectos relacionados ao turismo, tais como na paralisação de eventos de grande porte, no fluxo de turistas, bem como nas contas públicas.

Destaca-se que a pesquisa aqui apresentada entende o turismo como um elemento importante do processo de reprodução do capital no espaço, e que revela intencionalidades dos atores que lideram este 
processo. Além disso, como parte de uma totalidade, pode colaborar para interpretar os aspectos sociais e históricos, bem como os conflitos e as contradições da sociedade contemporânea.

Município do Rio de Janeiro: trajetória territorial turística nas últimas três décadas

A capital fluminense teve seu processo de turistificação no início do século XX e, segundo Fratucci, Spolon e Machado (2016), foi a partir da década de 1990 que houve a complexificação de seu produto turístico e a consolidação da atividade em seu espaço urbano. A grande mudança ocorreu com os preparativos para sediar a Conferência de Meio Ambiente da Organização das Nações Unidas (Rio 92).

O prefeito César Maia, em 1993, inspirou-se em experiências internacionais pioneiras, seguindo o exemplo bem-sucedido da cidade de Barcelona ao sediar os Jogos Olímpicos de 1992. O poder executivo optou pela contratação de consultores catalães para a elaboração de um plano estratégico com ênfase no marketing urbano, denominando o plano de "Rio sempre Rio" (GUANAIS; FISCHER, 1999). O plano iniciou-se na gestão César Maia (1993-1996) e percorreu quatro gestões municipais até 2016.

Sendo assim, foram mais de vinte anos de uma política orientada sobre a lógica da promoção urbana do município, independente das diferenças político-partidárias (PASQUOTTO, 2016). Tais experiências resultaram em inúmeras intervenções urbanísticas realizadas na preparação do município para sediar megaeventos importantes no cenário internacional, tais como os Jogos Pan-americanos (2007); Jogos Militares (2011); Conferência das Nações Unidas sobre Desenvolvimento Sustentável, conhecida também como 'Rio + 20' (2012); a Copa das Confederações (2013); Jornada Mundial da Juventude (2013); Copa do Mundo (2014); e, por fim, Jogos Olímpicos de Verão e Jogos Paraolímpicos (2016).

Dados do IBGE revelaram que, entre 2013 (ano anterior à Copa) e 2016 (ano dos Jogos Olímpicos de Verão e Jogos Paraolímpicos), o PIB municipal teve crescimento aproximado de $18 \%$. Ainda, segundo o Instituto, no mesmo período, o setor de Serviços cresceu cerca de $21 \%$ (IBGE, 2018). Por sua vez, a participação do setor de viagens e turismo no PIB carioca aumentou de 3,7\% para 4,9\%, segundo o WTTC (WTTC, 2019).

Apesar dos investimentos, a realidade urbana da capital fluminense e sua população não logrou êxito em diversos legados prometidos - em particular no que tange ao incremento dos fluxos de turistas -, sendo o problema da violência urbana um importante fator que explica o fracasso no alcance dessa meta (CABRAL, 2019), bem como a crise econômica e política, com inúmeros escândalos de corrupção.

A manutenção no ritmo de crescimento do PIB após os grandes eventos apresentava-se como um grande desafio, já sendo esperada uma retração. Entretanto, na reta final dos preparativos para os Jogos Olímpicos de Verão e Paraolímpicos de 2016 foi decretado estado de calamidade pública no âmbito da 
administração financeira do Estado do Rio de Janeiro, conforme Decreto Estadual no 45.692, de 17 de junho de 2016 (RIO DE JANEIRO, 2016). Com isso, deflagrou-se uma crise que afetou diretamente diversos serviços e setores de responsabilidade do Estado, como mobilidade, segurança pública, dentre outros. Esses, combinados ao contexto de crise econômica e política nacional, afetaram também o setor de turismo no município e no Estado do Rio de Janeiro. A participação do setor no PIB municipal diminuiu consideravelmente, comparada aos níveis precedentes aos grandes eventos, atingindo o valor de 3,7\%, o mesmo observado em 2013 (WTTC, 2014). Sendo assim, com o fim dos recursos públicos e privados oriundos da preparação do município para sediar os megaeventos, associados à crise econômica e política que o País enfrentou em 2015, a queda de preço do petróleo e gás ${ }^{2}$ e crises de corrupção no Estado, o estado e a capital emergiram em uma recessão econômica que permaneceu até 2018 (FIRJAN, 2019).

Em 2019, o setor demonstrou alguns avanços importantes. Segundo entrevista concedida pela Diretora da Secretaria Especial de Turismo e Legado Olímpico, Ângela Mesquita (SETURLEO-Rio), o ano de 2019 foi considerado muito produtivo para todo o setor de Turismo carioca, criando grandes expectativas para o ano de 2020, com a promessa de recuperação frente à crise enfrentada nos anos anteriores. A promessa, entretanto, não se concretizou, em razão do avanço da Pandemia de Covid-19 no Brasil e das ações empreendidas para a sua contenção, que afetaram diretamente a economia e, em especial, o Turismo. Assim, no ano de 2020, o setor, no município do Rio de Janeiro, logrou êxito apenas nos primeiros meses, como exemplo, durante o carnaval 2020, que superou as expectativas dos organizadores ${ }^{3}$.

Essa recuperação econômica foi interrompida com a pandemia de Covid-19, reconhecida pelo governo federal em 6 de fevereiro de 2020, por meio da Lei no 13.979 (BRASIL, 2020a), que estabeleceu medidas para o enfrentamento da emergência de saúde pública de importância internacional. Foram recomendados o isolamento social, quarentena, determinação e realização compulsória de tratamento de saúde e redução ou suspensão das atividades de trabalho nas repartições públicas (BRASIL, 2020a).

Em 12 de março do mesmo ano, o governo do município do Rio de Janeiro publicou o Decreto no 47.246 (RIO DE JANEIRO, 2020a), que regulamentou a Lei no 13.979, estabelecendo as primeiras medidas para o enfrentamento da emergência de saúde pública em decorrência da expansão dos casos da doença no município. Entre março de 2020 a fevereiro de 2021, foram confirmados 206.827 casos no município, dos quais 18.841 de pessoas vieram a óbito (RIO PREFEITURA, 2021b).

\footnotetext{
${ }^{2}$ Setor que ocupa lugar de destaque na economia fluminense.

${ }^{3}$ De acordo com os dados divulgados pela prefeitura, o município recebeu em torno de 2,1 milhões de turistas no carnaval do ano de 2020. Mais de 10 milhões de pessoas circulando durante o carnaval, maior número de navios internacionais dos últimos 20 anos atracando no Píer Mauá, ocupação hoteleira em quase 100\%, R \$ 4 bilhões em movimentação econômica e um número recorde de dias de folia. Durante o carnaval, em fevereiro, foi registrado na capital fluminense um movimento na economia de R\$ 4 bilhões, sendo 8\% superior ao ano de 2019 (RIO PREFEITURA, 2020a).
} 
Em conformidade com o Painel COVID RJ (RIO PREFEITURA, 2021b), o município teve uma taxa de incidência de 3.104,9 por 100 mil habitantes, taxa de mortalidade de 282,8 por 100 mil habitantes e taxa de letalidade do mundo $(10,7 \%)$ (CARRO; VASCONCELOS, 2020). A letalidade no município pode ser considerada alta se comparada ao Brasil $(2,4 \%)$ e ao estado do Rio de Janeiro $(5,6 \%)^{4}$. Quanto à oferta de leitos hospitalares, mesmo antes da pandemia de Covid-19, o município do Rio de Janeiro apresentava uma série de deficiências no setor de saúde, o que piorou com o aumento de hospitalizações por causa da crise sanitária (RIO PREFEITURA, 2021b). A Defensoria Pública do estado do Rio de Janeiro divulgou um estudo indicando que na região metropolitana, aproximadamente duas mil pessoas infectadas pela Covid-19 faleceram enquanto aguardavam internação (LACERDA, 2020).

O combate à Covid-19 apresentou uma série de peculiaridades na capital fluminense. O governo municipal, em 19 de março de 2020, instituiu o Gabinete de Crise da Prefeitura da Cidade do Rio de Janeiro, com o objetivo de organizar e executar a integração das operações dos órgãos e entidades da Administração Pública Municipal nas ações em prol da causa da crise sanitária (RIO DE JANEIRO, 2020b). As ações executadas pelo município visavam a manutenção dos direitos fundamentais, especificamente à saúde, e foram realizados, em um primeiro momento, de março a maio de 2020, com ações muito restritivas para conter a disseminação da doença. No entanto, meses depois, iniciaram-se as flexibilizações das restrições.

No âmbito estadual, em 16 de março de 2020, por meio do Decreto no 46.973 (RIO DE JANEIRO, 2020c), foi reconhecida a situação de emergência na saúde pública do Estado do Rio de Janeiro. Em razão do contágio e das medidas de enfrentamento da propagação decorrente do novo coronavírus, foi criado o Gabinete Ampliado de Crise para Assessoramento ao Enfrentamento das Novas Etapas da Pandemia de Covid-19, através do Decreto no 47.020, de 03 de abril de 2020 (RIO DE JANEIRO, 2020d). Em junho de 2020, foi lançado o "Pacto Estadual Social pela Saúde e Economia", um sistema de classificação com bandeiras, cujas cores vinculam a situação da pandemia de Covid-19, e orientam a flexibilização ou a suspensão de atividades comerciais e a circulação de pessoas com o objetivo de orientar a sociedade fluminense quanto às condições necessárias para a retomada das atividades econômicas (GOVERNO DO ESTADO DO RIO DE JANEIRO, 2020).

Como resultado ao setor de turismo, o governo do estado criou o "Selo Turismo Consciente", em junho de 2020, no qual empresários do setor têm acesso a um portal on-line, declarando-se aptos à prestação de serviços. Com isso, permitiu-se o controle do que está ou não funcionando no estado do Rio de Janeiro, sendo atualizado por cada prefeitura. Em dezembro, foi lançado o projeto "Rio o seu melhor presente", que se trata de uma plataforma digital em que produtos turísticos de todo o estado são promovidos, sendo oferecidos descontos para os consumidores, a fim de estimular o retorno às viagens.

${ }^{4}$ Durante o período estudado, houve oscilação no crescimento da doença, sendo o maior crescimento registrado de abril a junho e de agosto a setembro de 2020. A partir de novembro, não houve melhoria do quadro, mas seu agravamento. 
Retomando ao âmbito municipal, em 02 de junho de 2020, por meio do Decreto № 47.488 (RIO DE JANEIRO, 2020b), foi instituído o Comitê Estratégico para desenvolvimento, aprimoramento e acompanhamento do Plano de Retomada, em decorrência dos impactos da pandemia. A partir do Comitê Estratégico, foram criadas as "Regras de Ouro" ${ }^{5}$, voltadas à mitigação da transmissão e contágio do vírus . Portanto, estabelecimentos e prestadores de serviços que cumprirem as ações recomendadas podem requerer o "Selo de Conformidade com Medidas Preventivas da Covid-19", para atestar o cumprimento de tais regras (RIO DE JANEIRO, 2020b).

Esse plano também apresenta critérios para a classificação das atividades econômicas na retomada. Tais critérios devem considerar a capacidade de leitos disponíveis nos Centro de Unidades Intensiva (CTI), variação de óbitos, crescimento de casos internados e a variação de novos casos a partir dos números e percentuais que são referência para determinar os procedimentos que estabelecem as fases que vão de 1 - risco baixo - a 6 - risco alto.

De forma resumida, a Fase 1, que se iniciou em 02 de junho de 2020, caracterizou-se pela liberação parcial de atividades esportivas ao ar livre, mantidas as restrições em praias, espaços culturais e atrativos turísticos. A Fase 2, iniciada na segunda quinzena do mesmo mês, flexibilizou a abertura de shoppings com horários reduzidos. A Fase 3 possibilitou a abertura do comércio, limitando a abertura de bares e restaurantes com $50 \%$ de sua capacidade original de atendimento. Na última subfase, em julho, houve a liberação de parques, jardins, praças e praias (para práticas individuais). A Fase 4, em meados de julho, liberou, pontualmente, alguns dos importantes atrativos turísticos do município (Pão de Açúcar, Cristo Redentor e Roda Gigante). A Fase 5, no início de agosto, permitiu a abertura de todos os atrativos turísticos, com atendimento de $50 \%$ de sua capacidade. A Fase 6 , iniciada em setembro, somente exigia que os protocolos das regras de ouro fossem seguidos.

Os segmentos "turismo" e "cultura" obtiveram a mesma estratégia de tratamento quanto às restrições e às medidas de flexibilização, sendo permitido manter-se "aberto com restrições". Por outro lado, segmentos importantes do setor de turismo, tais como o de eventos e lazer, foram tratados de forma mais rígida para a retomada.

O setor de hospedagens manteve-se em funcionamento durante todo o período avaliado, com restrições internas relacionadas aos espaços coletivos (tais como piscinas, saunas e academias de ginástica), que foram flexibilizados a partir da fase $6 \mathrm{~A}$, e totalmente liberados no mês de outubro, mantendo os protocolos das regras de ouro.

\footnotetext{
${ }^{5}$ As "Regras de Ouro" estão disponíveis em: https://bit.ly/3cC4QA5https://doweb.rio.rj.gov.br/apifront/portal/edicoes/imprimir_materia/659805/4588.
} 
Em relação à questão financeira, em outubro, o segmento de cultura, por meio do Decreto no 48.002 , de 09 de outubro de 2020 (RIO DE JANEIRO, 2020e), recebeu aporte de R\$ 39.392.682,9 nas ações emergenciais destinadas ao setor, com base na Lei Aldir Blanc. De forma paliativa, pode-se considerar que favoreceu agentes do setor de turismo, mas cujos impactos ainda demandam tempo para poderem ser avaliados.

Ao assumir a nova gestão municipal, em janeiro de 2021, o prefeito Eduardo Paes revelou uma postura mais ativa ao enfrentamento à crise sanitária em relação ao governo anterior. Em fevereiro de 2021, foi iniciada a vacinação no município, porém, ainda em um ritmo muito tímido. Até o fim do mês de fevereiro, apenas 5,14\% da população havia recebido a primeira dose da vacina (RIO PREFEITURA, 2021b).

\section{O impacto da pandemia nos eventos e nos fluxos turísticos por eles estimulados}

Após anos de investimento na atração de megaeventos e, usualmente, caracterizado como um município com "vocação natural para eventos", o Rio de Janeiro amarga o prejuízo da paralisação deste setor. Segundo a presidente da ABEOC, Adriana Carvalho (Informação verbal) ${ }^{6}$, o segmento de eventos foi o mais afetado com a pandemia, pois continuava paralisado, enquanto outros setores retornavam às suas atividades, mesmo que parcialmente (tais como a hotelaria, agenciamento, restaurantes, dentre outros). Ainda, acrescentou que, além dos protocolos sanitários que impedem/restringem a realização de eventos, a ausência dos patrocinadores é um fator preocupante - uma vez que existe receio da imagem da empresa estar associada a um evento disseminador da Covid-19.

É importante salientar que para a realização do réveillon em Copacabana, na virada do ano de 2019, por exemplo, o patrocínio de empresas privadas girou em torno de $\mathrm{R} \$ 5,5$ milhões (EXAME, 2019). Situação diferente da vivenciada em dezembro de 2020, quando diante da ausência dos patrocinadores, e somada à necessidade de conter a disseminação do coronavírus, resultou no cancelamento da festa.

Assim como ocorreu no Réveillon 2020/2021, visando conter o avanço da contaminação por Covid-19, o tradicional carnaval carioca ${ }^{7}$ teve o mesmo desfecho. A Prefeitura do Rio de Janeiro publicou o Decreto no 48.500 com a proibição da realização e concentração de blocos de carnaval ou escolas de samba durante o período de 12 a 22 de fevereiro de 2021 em todo o município (RIO DE JANEIRO, 2021). Apesar dos esforços

\footnotetext{
${ }^{6}$ CARVALHO, Adriana. Estudo Internacional sobre "Turismo em Tempos de Pandemia". [Entrevista concedida a Carlos Lidizia, Cláudia Moraes e Isabela Fogaça no âmbito do Grupo de Pesquisa Turismo em Tempo de Pandemia]. Video (78:35 min). Acesso em 17 de dezembro de 2020.

${ }^{7}$ No carnaval de 2020, mesmo com o coronavírus já em circulação em alguns países (em especial, no continente europeu), a tradicional festa carioca aconteceu normalmente entre os dias 22 e 26 de fevereiro de 2020, e superou as expectativas dos organizadores com relação ao público e receitas. No último dia deste carnaval de 2020, feriado de quarta-feira de cinzas, o Ministério da Saúde divulgou a confirmação do primeiro caso de coronavírus no Brasil (MINISTÉRIO DA SAÚDE, 2020).
} 
empreendidos pelo poder público para conter as aglomerações clandestinas, foram muitas as imagens e reportagens veiculadas na mídia sobre festas que desrespeitaram as orientações das autoridades - tanto na noite do réveillon quanto nos dias de carnaval.

Outro grande evento que não acontecerá na capital fluminense no ano de 2021 é o "Rock in Rio", um dos principais festivais de música do mundo, e importante atração para turistas nacionais e estrangeiros ao município. O festival, que acontece a cada dois anos no município do Rio de Janeiro, tinha programada sua nona edição para setembro e outubro de 2021, porém, foi adiada para setembro de 2022 (AGÊNCIA BRASIL, 2020). Em sua última edição (2019), o evento teve impacto econômico de $R \$ 1,7$ mil milhão de reais e a ocupação hoteleira durante o período do evento foi de $80 \%$, com 700 mil visitantes ao longo dos sete dias (BALASSIANO, 2019).

\section{O impacto da pandemia nos fluxos de acordo com os modais de transporte}

Na ausência dos eventos e diante das restrições impostas para contenção da pandemia, foi significativa a diminuição no fluxo de turistas chegando ao município do Rio de Janeiro nos principais terminais de entrada. Nos aeroportos, Internacional Antônio Carlos Jobim (Galeão) e Santos Dumont, apesar de não terem tido suas atividades totalmente suspensas com a pandemia, foi possível constatar o movimento reduzido devido às restrições impostas (Tabela 1).

Tabela 1. Número de passageiros (embarques/desembarques) nos aeroportos cariocas. Fonte: Dos autores com dados do Riogaleão (2021); INFRAERO (2021)

\begin{tabular}{ccc}
\hline Ano & Aeroporto Tom Jobim & Aeroporto Santos Dumont \\
\hline 2019 & 13.507 .881 & 9.091 .258 \\
2020 & 4.635 .123 & 4.940 .034 \\
Diferença & 8.872 .758 & 4.151 .224 \\
\hline
\end{tabular}

Como pode ser observado, houve redução de cerca de $34 \%$ no número de passageiros nacionais e estrangeiros (considerando embarques e desembarques), que utilizaram os terminais aeroportuários da capital fluminense no ano de 2020 em comparação aos dados de 2019. Com relação ao modal rodoviário, no comparativo entre os primeiros semestres de 2019 (2.873.151 passageiros) e 2020 (1.417.771 passageiros) ocorreu uma expressiva diminuição, da ordem de $49 \%$, no quantitativo de pessoas que embarcaram na Rodoviária do Rio (RODOVIÁRIA DO RIO, 2020). 
Quanto ao mercado de turismo de cruzeiros marítimos, este também foi sensivelmente afetado pela pandemia de Covid-19 no município do Rio de Janeiro. Sobretudo a partir do final da temporada 2019-2020, com o cancelamento dos cruzeiros de alguns navios, que atingiram a paralisação total das atividades na temporada 2020-2021 (Tabela 2).

Tabela 2. Número de passageiros (embarques/desembarques) no Píer Mauá. Fonte: Píer Mauá (2021)

\begin{tabular}{cccc}
\hline Temporada & Passageiros & Embarques e Desembarques & $\begin{array}{c}\text { Cancelamentos } \\
\text { 2020 (Covid-19) }\end{array}$ \\
\hline $2018 / 2019$ & 291.678 & 103 & 12 \\
$2019 / 2020$ & 325.723 & 99 & 9 \\
Diferença & 34.045 & 4 & 3 \\
\hline
\end{tabular}

Os dados sobre o embarque e desembarque de passageiros revelam que, se a pandemia não ocorresse, o setor teria resultados muito mais significativos. Pela temporada ocorrer entre a segunda quinzena de outubro e a primeira quinzena de abril, pode-se afirmar que a pandemia afetou apenas o final da temporada 2019-2020 e, assim, o mercado de turismo de cruzeiros, em um primeiro momento, não foi totalmente atingido.

Por sua vez, a temporada 2020-2021 não teve programação de navios para aportar no Pier Mauá (PIER MAUÁ, 2020), afetando o setor de turismo de cruzeiros. Isso atingiu também a cadeia de serviços em torno do terminal, tais como guias de turismo e agências de receptivo, bem como o fluxo de visitantes em atrativos. Notadamente, o Monumento Natural dos Morros do Pão de Açúcar e da Urca e o Parque Nacional da Tijuca que, juntos, concentram o fluxo turístico de cruzeiristas que realizam roteiros no destino Rio de Janeiro (FRAGA; BOTELHO; VILANI, 2015) e estão entre os dez atrativos mais procurados (ARRUDA, SILVA, MARIANI, 2020), o que pode indicar o impacto da pandemia de Covid-19 no setor de turismo.

Para entender o significado do impacto para o setor, vale ressaltar que o mercado de turismo de cruzeiros movimenta bilhões de dólares, é concentrado em apenas três companhias, que aglutinam operações em áreas do Caribe e Mediterrâneo, e restrito a uma demanda formada principalmente por turistas dos Estados Unidos e do continente europeu. Na perspectiva da oferta, a América do Sul representa 4,5\% do total do mercado (DOWLING, WEEDEN, 2017; CLANCY, 2017). No Brasil, o mercado é considerado com potencial de crescimento, sobretudo devido à sua característica geográfica. No entanto, a infraestrutura portuária é um dos gargalos na maioria dos portos brasileiros (ROBLES; GALVÃO; PEREIRA, 2015). 
No caso específico do município do Rio de Janeiro, em sintonia ao processo de transformações urbanas do projeto Porto Maravilha ${ }^{8}$, a Estação Marítima de Passageiros do Porto do Rio de Janeiro - conhecida por Pier Mauá (PIER MAUÁ, 2020) - ao ser delegada à iniciativa privada por meio de concessão, foi reformada, tornando-se um importante terminal internacional, conectado com atrativos do entorno. Essas alterações ampliaram o fluxo de turistas internacionais para além da via aérea e, mesmo que temporariamente, o aumento do fluxo em atrativos naturais e culturais (FRAGA; BOTELHO; VILANI, 2015). A partir disso, pode-se afirmar que os investimentos urbanísticos planejados para a zona portuária do município do Rio de Janeiro, potencializados pela consolidação do mercado de cruzeiros marítimos internacionais (antes da pandemia, em ascensão), transformaram esse território em lócus preferencial no conjunto do processo de apropriação do território pelo capital.

O impacto da pandemia nos fluxos de visitação aos atrativos

O Monumento Natural dos Morros do Pão de Açúcar e da Urca, onde está o Teleférico do Pão de Açúcar (conhecido, popularmente, por Bondinho), é uma Unidade de Conservação gerenciada pela Prefeitura, enquanto uma empresa concessionária opera os serviços de visitação no Bondinho. O Parque Nacional da Tijuca, onde se localiza o Morro do Corcovado e o Monumento do Cristo Redentor, é administrado pela esfera federal, e duas concessionárias operam os serviços do Trem do Corcovado e do transporte rodoviário. Ambas as Unidades de Conservação são atrativos turísticos que tiveram a visitação suspensa entre os meses de março e agosto de 2020, em função da pandemia de Covid-19.

Em agosto de 2020, retomaram suas operações de forma gradativa, com estabelecimento das "Regras de Ouro", e com a limitação do número de visitantes, após negociações junto ao Comitê Gestor da Pandemia, coordenado pela Prefeitura do Rio de Janeiro. Neste caso, o Bondinho, o Trem do Corcovado e o transporte rodoviário passaram a operar, no Programa de Retomada, com 50\% da sua capacidade (DIÁRIO DO RIO, 2020) e limite de até 200 pessoas na trilha de acesso ao Morro da Urca (CÂMARA TÉCNICA DE COMUNICAÇÃO DO MONUMENTO NATURAL DOS MORROS DO PÃO DE AÇÚCAR E URCA, 2020). Porém, a reabertura, que buscou incentivar o morador do município a visitar os atrativos turísticos por meio de descontos nos ingressos, gerou aglomeração de pessoas em alguns locais (DIÁRIO DO RIO, 2020).

\footnotetext{
${ }^{8}$ O Píer Mauá está inserido na Área de Especial Interesse Urbanístico (AEIU) da Região do Porto do Rio. Por meio de uma Parceria Público-Privada entre Companhia de Desenvolvimento Urbano da Região do Porto do Rio de Janeiro (CDURP) e a concessionária Porto Novo, executam o projeto Porto Maravilha, que prevê a execução de obras e serviços entre 2011 e 2026 (PORTO MARAVILHA, 2015).
} 
Como referência do impacto da pandemia, cabe salientar que o Monumento Natural dos Morros do Pão de Açúcar e da Urca recebe, aproximadamente, 1,8 milhão de visitantes por ano, sendo cerca de 1,5 milhão pelo teleférico (Bondinho), enquanto 380 mil visitantes utilizam o acesso por trilha (MONA, 2012) ${ }^{9}$.

Por sua vez, o Parque Nacional da Tijuca, que recebeu o título de Unidade de Conservação federal brasileira com o maior índice de visitas registradas, teve contabilizado, em 2019, 2.959.444 visitas nos quatro setores (Corcovado, Floresta da Tijuca, Pedra da Gávea e Pretos Forros). Do total de visitas, 1.940.327 concentraram-se no setor Morro do Corcovado, representando cerca de 65,5\% do total, o que revela a importância econômica da visitação desta área onde estão os serviços concessionados à iniciativa privada. Dados comparativos entre os anos de 2019 e 2020, mostraram que, em 2020, a Unidade recebeu 1.395.356 visitantes, 52,85\% menos do que o ano anterior; e 860.478 pessoas visitaram o setor Corcovado, 55,65\% menos em relação à 2019 (PARQUE NACIONAL DA TIJUCA, 2021).

Diante do exposto, verifica-se que os principais atrativos turísticos do destino Rio de Janeiro são áreas protegidas administradas pelo poder público, mas que abrigam concessões de serviços operadas pela iniciativa privada. Com o fechamento dos atrativos, ambos deixaram de arrecadar, afetando, assim, toda a cadeia produtiva, tais como os guias de turismo e demais trabalhadores.

\section{O impacto da pandemia nos empregos, impostos e receitas do setor de turismo}

Os impactos na geração do trabalho foram observados no município do Rio de Janeiro, assim como ocorreu com o fluxo de turista. Houve a intensificação expressiva do número de desligamentos combinada à expressiva diminuição das admissões, diretamente relacionadas às medidas de restrição de mobilidade e, portanto, redução dos fluxos turísticos e de lazer doméstico.

Dados do Cadastro Geral de Empregados e Desempregados (CAGED) do governo federal apontaram uma movimentação negativa para todas as oito Atividades Características do Turismo (ACTs) relacionadas ao turismo na capital fluminense, no comparativo entre os anos de 2019 e 2020. O desempenho dos empregos formais nas ACTs, em 2019, teve saldo positivo de 3.611 empregos (70.072 admissões contra 66.461 desligamentos). Por sua vez, em 2020, o total de admissões nas ACTs, na capital fluminense, foi de 37.817 contra 63.197 desligamentos, perfazendo um saldo negativo de 25.290 postos formais de trabalho. Logo, notase uma variação negativa de cerca de $700 \%$ no saldo de empregos no comparativo entre os dois anos analisados (BRASIL, 2020b; BRASIL, 2020c).

\footnotetext{
${ }^{9} \mathrm{O}$ índice de visitas nesse atrativo para o período referente à pandemia não foi publicizado e/ou disponibilizado.
} 
Os dados do CAGED apontaram, ainda, que o incremento dos saldos negativos se intensificou entre os meses de março e agosto de 2020, com números absolutos atípicos (já considerando o fenômeno da sazonalidade do setor), quando comparados ao mesmo período do ano anterior. Esse período coincide com a implementação, pelo poder público, das principais medidas de enfrentamento da crise sanitária, dentre as quais pode-se ressaltar aquelas restritivas de mobilidade (Figura 1).

Figura 1. Saldo de Empregos nas ACTs no município do Rio de Janeiro - 2019-2020. (CAGED). Fonte: Brasil (2020b); Brasil (2020c).

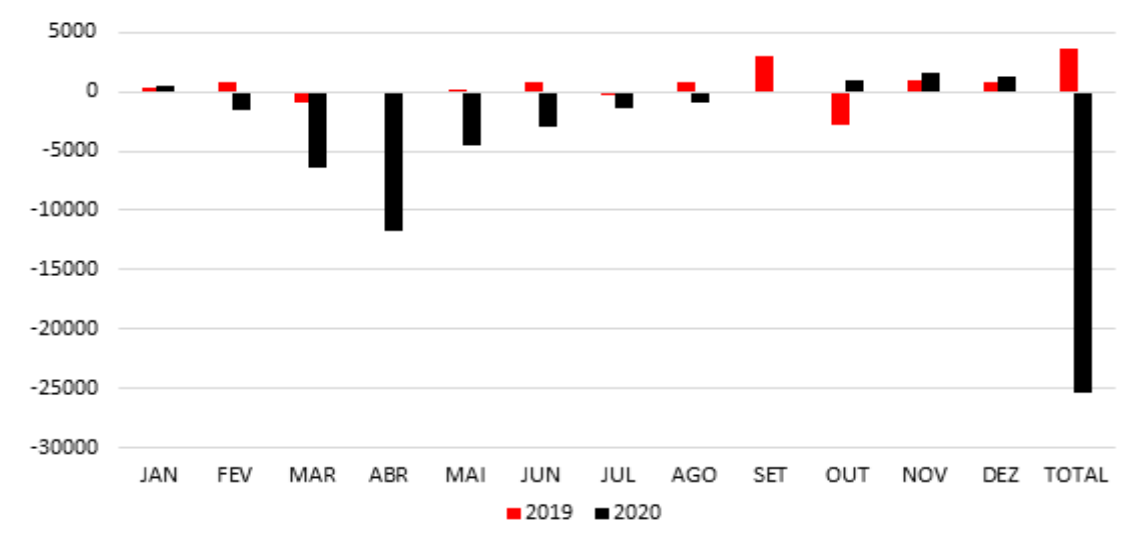

Figura 2. Saldo de Empregos nas ACTs no município do Rio de Janeiro - 2019-2020. (CAGED). Fonte: Brasil (2020b); Brasil (2020c).

Com efeito, as primeiras medidas de enfrentamento da crise surgiram no município do Rio de Janeiro, no mês de março de 2020, incluindo medidas de lockdown. A partir de julho e agosto, após o estabelecimento de diversos protocolos de segurança e gestões entre o poder público e o trade, algumas ACTs começam a ser lentamente retomadas no destino. Tal fato é corroborado pelo saldo positivo nos postos de trabalho no setor, no último trimestre de 2020, auxiliado pelo desempenho das atividades de hotelaria (saldo trimestral positivo de 803 postos), restaurantes e similares (saldo trimestral positivo de 2793 postos), o que reverteu a tendência observada desde o mês de março daquele ano. Registraram-se, no último trimestre de 2020, 3.767 empregos, contrastando com o saldo negativo de 1.202 empregos no último trimestre de 2019. (Figura 2).

As incertezas a respeito do futuro e a insegurança por parte dos empresários têm afetado também as tipologias de contratação, com crescimento da modalidade de contratação temporária, bastante comum no turismo em razão da sazonalidade. Muito embora não haja informações específicas sobre o setor de turismo, para o nosso recorte espacial e temporal, dados gerais da Associação Brasileira do Trabalho Temporário (ASSERTTEM) apontaram que, em 2020, houve, no Brasil, acréscimo de cerca de $35 \%$ nessa modalidade de contratação, quando comparado ao ano de 2019. Desse total, $10 \%$ ocorreram no setor de comércio e $25 \%$ no setor de serviços, que inclui o turismo (ASSERTTEM, 2021). Tal fato pode indicar que a lenta retomada de admissões no setor esteja centrada nessa modalidade de contratação. 
No que se refere aos impostos no setor de Serviços, observou-se uma diminuição em sua arrecadação, no comparativo entre os primeiros semestres de 2019 e 2020, período de fechamento das principais atividades no município. Dados do Portal da Transparência da Prefeitura Municipal do Rio de Janeiro (RIO PREFEITURA, 2021a), revelaram que a arrecadação do Imposto sobre Circulação de Mercadorias e Serviços (ICMS), de competência estadual, teve uma redução de cerca de 2,60\%, e do Imposto Sobre Serviços (ISS), de competência municipal, de aproximadamente $4,25 \%$.

Em relação às Receitas Gerais do município, houve pequena elevação, de aproximadamente $2,58 \%$. Em 2019, o município contabilizou R\$ 28.752.805.221,50 ao passo que, em 2020, acumulou $R \$ 29.495 .126 .939,67$ (RIO PREFEITURA, 2021a). Em parte, esse aumento pode ser explicado através dos recursos para enfrentamento à Covid-19 repassados aos municípios - e que, de fato, ficam discriminados no sítio eletrônico da própria contabilidade do município carioca, no item "Contas Rio".

Entretanto, vale destacar que, observadas isoladamente as Receitas Municipais de Serviços ${ }^{10}$, houve queda considerável em torno de 35,31\% em arrecadação, passando de $\mathrm{R} \$ 122.683 .661,99$, em 2019, para R\$ 79.361.954,98, em 2020 (RIO PREFEITURA, 2021a). Estes dados corroboram, assim, a diminuição geral em torno do setor de Serviços, observada também através do ICMS e do ISS.

\section{CONSIDERAÇÕES FINAIS}

A implementação das políticas de contenção de avanço da pandemia, em um primeiro momento de cunho sanitário, representadas pelas medidas restritivas de mobilidade e isolamento social, trouxeram sérios impactos à economia carioca, à medida que houve a necessidade de seu prolongamento.

Ao criar o Gabinete de Crise e documentos legais, que pudessem realizar um ordenamento e controle na crise sanitária, o governo municipal teve uma postura de defensor do isolamento e criou normas alinhadas com as recomendações internacionais.

O que se pensava tratar de um problema de curto prazo, perdura há um ano, com reaberturas e contingenciamentos. Órgãos do setor público e o trade ensaiam alternativas isoladas e integradas para a retomada gradual e segura das atividades, tais como as "Regras de Ouro" do município; o selo estadual "Turismo Consciente"; e a iniciativa "Rio, o seu melhor presente".

\footnotetext{
${ }^{10}$ Vale sublinhar que, para a administração municipal do Rio de Janeiro, os valores de Receita Municipal de Serviços não são os mesmos que os valores de Imposto Sobre Serviços (ISS).
} 
Concomitantemente, o avanço da nova "onda" da pandemia - com variantes do vírus e a morosidade do governo federal quanto às ações a respeito da vacina e dos protocolos científicos de segurança - preocupam as autoridades locais que encontram, cada vez mais, resistências na implementação das medidas de controle sanitário, frente aos números crescentes de contaminação e mortes apresentados nos boletins epidemiológicos. Empresários e trabalhadores, diante dos impactos da primeira "onda" e agora da segunda ou terceira "onda", temem perdas financeiras, fechamento dos negócios e o desemprego, enquanto o poder público federal parece ignorar o iminente colapso da saúde pública e o escandaloso número de vidas humanas ceifadas.

As ações empreendidas, em grande medida pela atuação do Estado, para contenção da disseminação do vírus, notadamente as medidas de isolamento social e fechamento da indústria, comércio e serviços, tiveram grande impacto econômico nas áreas em que foram empreendidas. No turismo, tais medidas ganharam proporções consideráveis, especialmente aquelas relacionadas aos lockdowns, que atingiram diretamente os fluxos de visitantes e, por conseguinte, as ACTs, por natureza, altamente dependentes de tais fluxos.

No setor hoteleiro e de restaurantes e similares, foi registrado um saldo positivo no último trimestre de 2020, quando comparado ao mesmo período de 2019. Esse fato é decorrente das possibilidades geradas no contexto da pandemia, que revelaram a adoção de novas estratégias de negócios e novos comportamentos por parte do consumidor em tempos de pandemia, e pelas flexibilizações e adoção das Regras de Ouro.

Muito embora haja grande dificuldade no levantamento de dados quantitativos específicos para o setor de turismo, isoladamente, é possível afirmar, com base em algumas fontes governamentais e em entrevistas com representantes do setor público e do trade, que a crise sanitária e as ações empreendidas na tentativa de sua contenção trouxeram grandes perdas econômicas para o turismo, com o fechamento de muitas empresas e, consequentemente, o fechamento de muitos postos de trabalho.

Em um primeiro momento, decretou-se o lockdown, o que levou ao fechamento momentâneo e generalizado de todos os empreendimentos vinculados às principais ACTs do destino, alguns dos quais de forma definitiva, conforme apontado na entrevista feita com presidente da Federação de Convention \& Visitors Bureaux do Estado do Rio de Janeiro (FC\&VB-RJ). Em 2020, estimou-se que mais de 30\% dos bares, restaurantes e similares do município do Rio de Janeiro fechariam suas portas definitivamente a partir do lockdown implantado (informação verbal) ${ }^{11}$.

\footnotetext{
${ }^{11}$ NAVEGA, Marco. 2020. Estudo Internacional sobre "Turismo em Tempos de Pandemia". [Entrevista concedida a Carlos Lidizia, Cláudia Moraes e Isabela Fogaça no âmbito do Grupo de Pesquisa Turismo em Tempo de Pandemia]. Vídeo (85:25 min). Acesso em: 21 de dezembro de 2020.
} 
A presidente da SETURLEO-Rio, em 2020, mesmo sem números precisos, apontou o fechamento definitivo de muitos empreendimentos no setor de hotelaria no Rio de Janeiro (informação verbal) ${ }^{12}$. 0 segmento de eventos, conforme já afirmado, é apontado como um dos mais afetados pela implementação das políticas de isolamento social, pois ainda não retomou as atividades, mesmo após o estabelecimento de alguns protocolos de segurança sanitária.

Os sinais da postura negacionista a respeito da crise sanitária na esfera federal contrapõem-se às evidências científicas e aos protocolos internacionais, bem como às diversas ações nas outras esferas de governo (como observou-se no Rio de Janeiro), reduzindo a discussão e as ações a uma polarização econômico-sanitária e político-partidária, em que parece não haver meio termo. Os esforços locais para desenhar uma condução e saída conjunta da crise, mediada pela articulação com os atores envolvidos e pela garantia à saúde, parecem não encontrar respaldo nas ações federais, ganhando muitas resistências. A crise sanitária tem revelado, assim, uma grande dificuldade por parte do governo em exercer suas funções de coordenador e de garantidor do bem-estar da população, com altos custos sociais e ineficácia das ações empreendidas. Além das dificuldades existentes para obter apoio junto à esfera federal, em que pese o clima amistoso e otimista verificado entre o prefeito Eduardo Paes e o governador Claudio Castro no evento virtual citado no início deste artigo (ocorrido em janeiro de 2021) a situação vivida no final do mês de março de 2021 (dias antes da submissão deste artigo) ficou diferente em função da divergência de visões sobre a intensidade das restrições necessárias para conter a pandemia (GRINBERG, 2021).

Com o plano de retomada e as condições de instabilidade e incertezas, é provável que tanto os fluxos turísticos quanto os modais aéreos e rodoviários estabeleçam-se lentamente, mantendo forte impacto econômico nesses setores do turismo. No modal marítimo, a temporada dos cruzeiros, que se estende de outubro a abril, foi suspensa nos dois últimos meses da temporada de 2019/2020, além de toda a temporada de 2020/2021 e seu retorno está previsto somente para a temporada 2021/2022.

Os fluxos dos eventos praticamente deixaram de existir, pois foram impedidos de serem realizados, enquanto muitos foram adiados e outros cancelados. A presença dos eventos virtuais passou a ser alternativa. Meios de hospedagem e espaços de eventos prepararam-se para receber eventos híbridos com novas tecnologias.

A Secretaria de Estado de Turismo (Setur-RJ) teve a iniciativa de criar o Núcleo de Inteligência e Captação de Eventos (NICE) para dar visibilidade às feiras, congressos, exposições, simpósios e jornadas científicas. A

\footnotetext{
${ }^{12}$ MESQUITA, Ângela. Estudo Internacional sobre "Turismo em Tempos de Pandemia". [Entrevista concedida a Cláudia Moraes e Isabela Fogaça no âmbito do Grupo de Pesquisa Turismo em Tempo de Pandemia]. Vídeo (40:07 min). Acesso em 17 de dezembro de 2020.
} 
intenção é que as cidades fluminenses possam sediar eventos a partir da alta demanda no período póspandemia, incluindo, nesse contexto, os eventos do município do Rio de Janeiro.

Por fim, algumas das limitações deste artigo referem-se à fragilidade dos dados. No caso do CAGED, os números registraram apenas as atividades formais, não computando, portanto, as ocupações informais, diretamente ligadas ao turismo, das quais dependem o sustento de muitas famílias. A indisponibilidade de dados específicos sobre o trabalho informal no turismo, para nosso recorte espacial e temporal, impossibilitou uma análise mais acurada dos impactos para essa parcela de trabalhadores. Segundo Soares (2005), essa parcela está condicionada, cada vez mais, à perda progressiva da cidadania, revelada pela insegurança, marginalização social e afastamento dos sistemas de proteção oferecidos pelo Estado aos trabalhadores formais. Durante pesquisa sobre fluxos de pessoas nos eventos, atrativos e modais de transporte, não é incomum deparar-se com informações divergentes ou mesmo ausência de dados.

Estudos relacionados às metodologias de geração de dados e informações que contemplem a informalidade no turismo, podem contribuir com um dimensionamento mais efetivo quanto aos impactos da pandemia no setor de turismo, aos desdobramentos junto à sociedade e à orientação da política pública de turismo para apoiar e coordenar o processo de retomada da economia do turismo de forma segura e sustentável.

\section{REFERÊNCIAS}

Agência Brasil. Rock in Rio é adiado para setembro de 2022. Disponível em: https://agenciabrasil.ebc.com.br/geral/noticia/202103/rock-rio-e-adiado-para-setembro-de-2022 Acesso em: 05 de março de 2021.

ANAC. Agência Nacional de Aviação Civil. Dados e Estatísticas, 2019, 2020. Disponível em: https://www.anac.gov.br/assuntos/dadose-estatisticas Acesso em: 3 de junho de 2020.

ARRUDA, Diego de Oliveira; SILVA, Murilo Barbosa de Oliveira da; MARIANI, Milton Augusto Pasquotto. Análise da imagem do destino turístico Rio de Janeiro com base em comentários publicados no Tripadvisor. Revista de Administração Unimep, cidade, v. 18 , n. 2, p. 123-144, mai/ago. 2020.

ASSERTTEM. Associação Brasileira do Trabalho Temporário. CRESCE CONTRATAÇÃo DE TEMPORÁRIOS COM A PANDEMIA. Disponível em https://asserttem.org.br/noticia/cresce-contratacao-de-temporarios-com-a-pandemia-cresce-contratacao-detemporarios-com-a-pandemia Acesso em: 18 de fevereiro de 2020.

BARRETO, George Melo. A importância do Turismo de Proximidade: uma análise aplicada ao caso baiano. 2007. 129 f. Dissertação (Mestrado em Administração) - Escola de Administração, Universidade Federal da Bahia, 2007.

BRASIL. Lei de no 13.979, de 6 de fevereiro de 2020. Dispõe sobre as medidas para enfrentamento da emergência de saúde pública de importância internacional decorrente do coronavírus responsável pelo surto de 2019. Diário Oficial da União: seção 1, Brasília, DF, edição 27, p.1, 07 fev. 2020a. Disponível em: https://www.in.gov.br/en/web/dou/-/lei-n-13.979-de-6-de-fevereiro-de-2020$\underline{242078735}$ Acesso em: 07 de outubro de 2020.

BRASIL. Ministério do Trabalho e Emprego. Programa de Disseminação das Estatísticas do Trabalho. Cadastro Geral de Empregados e Desempregados (CAGED). Brasília: MTE, 2020b. Disponível em http://pdet.mte.gov.br/acesso-online-as-bases-de-dados Acesso em: 26 de agosto de 2020 . 
BRASIL. Ministério do Trabalho e Emprego. Programa de Disseminação das Estatísticas do Trabalho. Novo Cadastro Geral de Empregados e Desempregados (Novo CAGED). Brasília: MTE, 2020c. Disponível em http://pdet.mte.gov.br/novocaged?view=default Acesso em: 27 de agosto de 2020.

CABRAL, Maria Viviana de Freitas et al. Turismo em um cenário de guerra: os custos da violência e criminalidade para o setor de turismo e seus desdobramentos sobre os demais setores da economia fluminense. In: XVII ENCONTRO NACIONAL DA ASSOCIAÇÃO BRASILEIRA DE ESTUDOS REGIONAIS E URBANOS - ENABER, 17, 2019, Rio de Janeiro. [Anais...] ABER, 2019. p.1-15. Disponível em: https://brsa.org.br/wp-content/uploads/wpcf7-submissions/1193/Freitas-Cabral-et-2019.pdf Acesso em: 20 de janeiro de 2021.

CÂMARA TÉCNICA DE COMUNICAÇÃO DO MONUMENTO NATURAL DOS MORROS DO PÃO DE AÇÚCAR E URCA. Reabertura aos domingos e feriados. Disponível em: https://www.monapaodeacucar.com/ Acesso em 04 de março de 2021.

CARRO, Rodrigo. VASCONCELOS, Gabriel. Fracasso no combate a Covid foi fatal para Crivella. Valor Econômico. Política. Publicado em 30 de dezembro de 2020. Disponível em: https://valor.globo.com/politica/noticia/2020/12/30/fracasso-no-combate-a-covid-foifatal-para-crivella.ghtml Acesso em: 1de março de 2021.

CLANCY, Michael. Power and profits in the global Cruise Industry. In: DOWLING, Ross; WEEDEN, Clare (eds). Cruise ship tourism. 2 ed. $C A B I, 2017$.

DATABASE SEBRAE. Onde estão as empresas ligadas ao turismo no Brasil. Disponível em: https://datasebrae.com.br/mapaempresas-turismo/ Acesso em 20 de novembro de 2020.

O DIÁRIO DO RIO.COM. Cariocas fazem filas no primeiro dia de reabertura dos pontos turísticos do Rio. Diário do Rio. Redação. Publicado em 15/ ago 2020. Disponível em: https://diariodorio.com/cariocas-fazem-filas-no-primeiro-dia-de-reabertura-dospontos-turisticos-do-rio/Acesso em: 06 de março de 2021.

EXAME [institucional]. Réveillon em Copacabana terá patrocínio de $\mathbf{R} \mathbf{\$} \mathbf{5 , 5} \mathbf{~ m i ~ d e ~ e m p r e s a s ~ p r i v a d a s . ~ P u b l i c a d o ~ e m ~} 27$ de dezembro de 2019. Disponível em: <https://exame.com/negocios/reveillon-em-copacabana-tera-patrocinio-de-r-55-mi-de-empresasprivadas/>Acesso em 25 de janeiro de 2021.

FRAGA, Carla Conceição Lana; BOTELHO, Eloise Silveira; VILANI, Rodrigo Machado. Cruzeiros marítimos e unidades de conservação na cidade do Rio de Janeiro (RJ): um estudo sobre o Parque Nacional da Tijuca e o Monumento Natural dos Morros do Pão de Açúcar e da Urca. Caderno Virtual de Turismo. Rio de Janeiro, v. 15, n. 3., p. 317-330, dez. 2015.

FRATUCCI, Aguinaldo César; SPOLON, Ana Paula Garcia; MACHADO, Marcello de Barros Tomé. O turismo no Rio de Janeiro: da tríade praia-futebol-carnaval à complexidade da experiência turística contemporânea. In: NETTO, Alexandre Panosso; TRIGO, Luís Gonzaga Godoi (org). Turismo na América Latina: casos de sucesso. Assis: Triunfal Gráfica e Editora, 2016. 368p. p. 81-112.

FIRJAN. Publicações de Economia. Pesquisas sobre o Rio de Janeiro. Sobre o Brasil. Sobre você, empresário e cidadão. Disponível em https://www.firjan.com.br/publicacoes/publicacoes-de-economia/pib-brasil-e-rio-de-janeiro-resultados-e-projecoes.htm Acesso em: 10 de outubro de 2020.

FUNDAÇÃO GETULIO VARGAS - FGV. O Rio de Janeiro perde R\$ 5,5 bilhões sem carnaval. Portal FGV. Disponível em: https://www.portal.fgv.br/en/node/22139 Acesso em 20 de fevereiro de 2021.

GOVERNO DO ESTADO DO RIO DE JANEIRO. Secretaria de Desenvolvimento Econômico, Energia e Relações Internacionais. Pacto Social pela Saúde e pela Economia. 2020.

GUANAIS, Frederico Campos; FISCHER, Tânia. Entre Planos, Projetos e Estratégias: o caso Rio sempre Rio. Organizações \& Sociedade, Bahia, v. 6, n. 14, p. 39-63, jan/abr.1999.

GRINBERG, Felipe. Especialistas aprovam medidas de restrição no Rio e em Niterói, mas temem falta de coordenação. Jornal Extra. Disponível em: https://extra.globo.com/noticias/rio/especialistas-aprovam-medidas-de-restricao-no-rio-em-niteroi-mas-tememfalta-de-coordenacao-24937100.html. Acesso em 23 de março de 2021.

HALL, Michael; SCOTT, Daniel; GÖSSLING, Stefan. Pandemics, transformations and tourism be careful what you wish for. Tourism Geographies, China, v. 22, n.3, p. 577-598, 2020.

IBGE - Instituto Brasileiro de Geografia e Estatística. Pesquisa Produto Interno Bruto dos Municípios - 2018. 2018. Disponível em www.ibge.gov.br/brasil/ri/rio-de-janeiro Acesso em: 20 de fevereiro de 2020. 
IBGE - Instituto Brasileiro de Geografia e Estatística. ANUÁRIO ESTATíSTICO DE TURISMO - 2020. Vol. 47, ano Base 2019. IBGE: Brasília, 2020. Disponível em: http://www.dadosefatos.turismo.gov.br/2016-02-04-11-53-05.html. Acesso em: 10 de fevereiro de 2020.

INFRAERO. Estatísticas - Portal da Transparência - Infraero Brasil. 2021. Disponível em: https://transparencia.infraero.gov.br/estatisticas/ Acesso em: 01 de março de 2021.

LACERDA, Nara. Covid-19: quase 2 mil pessoas morreram por falta de leitos no estado do Rio de Janeiro. Brasil de Fato. Publicado em 04 de novembro de 2020. Disponível em: https://www.brasildefato.com.br/2020/11/04/quase-2-mil-pessoas-de-covid-19morreram-por-falta-de-leitos-no-estado-do-rio. Acesso em: 1 de março de 2021.

MINISTÉRIO DA SAÚDE. Linha do tempo coronavírus. 2020. Disponível em: https://coronavirus.saude.gov.br/linha-do-tempo Acesso em: 05 março 2021.

MONA. Monumento Natural dos Morros do Pão de Açúcar e da Urca. Resumo do Plano de manejo do Monumento Natural dos Morros do Pão de Açúcar e da Urca. Rio de Janeiro: Detzel Consulting, 2012. Disponível em: <https://www.monapaodeacucar.com/>. Acesso em: 01 de março de 2021.

PARQUE NACIONAL DA TIJUCA. Visitação no Parque Nacional da Tijuca. 2021. Disponível em: https://public.tableau.com/profile/parque.nacional.da.tijuca\#!/vizhome/VisitaonoParqueNacionaldaTijuca/VisitaonoPNT Acesso em: 04 de março de 2021

PASQUOTTO, Geise Brizotti. A utilização do Marketing Urbano no Planejamento Estratégico do Rio de Janeiro. Revista Nacional de Gerenciamento de Cidades, São Paulo, v. 04, n. 24, pp. 114-127. 2016.

PH DE NORONHA. Letalidade por Covid-19 no Rio está acima da média mundial. FIOCRUZ. Disponível em: https://portal.fiocruz.br/noticia/letalidade-por-covid-19-no-rio-esta-acima-da-media-mundial. Publicado em 01/set/2020. Acesso em 23 de março de 2021

PIER MAUÁ. Programação de Navios - Temporada 2019-2020. Disponível em: https://www.piermaua.rio/wpcontent/uploads/2020/03/Programac\%CC\%A7a\%CC\%83o-Dia\%CC\%81ria-de-Navios-Temporada-2019-2020-v09.pdf. Acesso em 2 de janeiro de 2021.

PORTO MARAVILHA. Quem somos. 2015. Disponível em: http://bit.ly/1Sda4yT Acesso em 04 de março de 2021.

RIO DE JANEIRO (Estadual). Decreto Estadual no 45.692 de 17 de junho de 2016. Decreta estado de calamidade pública, no âmbito da administração financeira do estado do Rio de Janeiro, e dá outras providências. Diário Oficial Estadual (DOE): RJ, p. 1, 17 jun. 2016 Edição Extraordinária.

RIO DE JANEIRO (Municipal). Decreto Rio no 47.246, de 12 de março de 2020. Regulamenta a Lei no 13.979, de 6 de fevereiro de 2020 e estabelece medidas para o enfrentamento da emergência de saúde pública de importância internacional decorrente do novo coronavírus no âmbito do Município do Rio de Janeiro. Procuradoria Geral do Estado do Rio de Janeiro. 12 mar. 2020 a.

RIO DE JANEIRO (Municipal). Decreto Rio no 47.488, de 2 de junho de 2020. Institui o Comitê Estratégico para desenvolvimento, aprimoramento, e acompanhamento do Plano de Retomada, em decorrência dos impactos da pandemia da COVID-19, e dá outras providências. 02 jun. 2020b. Disponível em: https://pge.ri.gov.br/comum/code/MostrarArquivo.php?C=MTEwNDU\%2C

RIO DE JANEIRO (Estadual). Decreto no 46.973, de 16 de março de 2020. Reconhece a situação de emergência na saúde pública do Estado do Rio de Janeiro em razão do contágio e adota medidas enfrentamento da propagação decorrente do novo coronavírus (COVID-19); e dá outras providências. 16 mar 2020c. Disponível em: https://pge.rj.gov.br/comum/code/MostrarArquivo.php?C=MTAyMjl\%2C Acesso em 10 dezembro 2020.

RIO DE JANEIRO (Estadual). Decreto no 47.020, de 03 de abril de 2020. Da nova redação ao inciso VIII do art. 4 do decreto no 47.006 de 27 de março de 2020. 03 abril 2020d. Disponível em: https://pge.ri.gov.br/comum/code/MostrarArquivo.php?C=MTA0ODY\%2C

RIO DE JANEIRO (Municipal). Decreto Rio № 48.002, de 9 de outubro de 2020. Regulamenta, no âmbito do Município do Rio de Janeiro, a Lei federal no 14.017, de 29 de junho de 2020, que dispõe sobre ações emergenciais destinadas ao setor cultural a serem adotadas durante o estado de calamidade pública reconhecido pelo Decreto Legislativo no 6, de 20 de março de 2020. 2020e.Disponível em: https://doweb.rio.rj.gov.br/apifront/portal/edicoes/imprimir materia/684908/4718

RIO DE JANEIRO (Municipal). Decreto Rio no 48.500, de 04 de fevereiro de 2021. Estabelece, em caráter excepcional, normas para o uso de áreas públicas e para o exercício de atividades econômicas durante o período compreendido entre 00h00min do dia 12 de 
fevereiro e 06h00min do dia 22 de fevereiro de 2021. 2021. Disponível em:

https://doweb.rio.ri.gov.br/apifront/portal/edicoes/imprimir materia/708544/4833. Acesso em 2 fev. 2021.

RIO PREFEITURA [Site Institucional]. Contas Rio. Portal da Transparência da Prefeitura Municipal do Rio de Janeiro. 2021.a. 2021a. Disponível em http://www.rio.rj.gov.br/web/contasrio/receita-por-fonte\#título Acesso em: 01 fevereiro 2021.

RIO PREFEITURA [Site Institucional]. Painel Rio Covid-19. [Site Institucional] 2021b.Disponível em:

<https://experience.arcgis.com/experience/38efc69787a346959c931568bd9e2cc4>Acesso em 1 fevereiro 2021.

ROBLES, Leo Tadeu; GALVÃO, Cassia Bömer; PEREIRA, Simone Rocha. Cruise shipping in Brazil: An emergent or established market? Tourism Management Perspectives, Queensland, v. 16, p. 298-305, out. 2015.

RIOGALEÃO. Movimentação Aeroportuária. RIOgaleão - Aeroporto Internacional Tom Jobim. 2021. Disponível em: https://www.riogaleao.com/corporativo/page/numeros-do-aeroporto Acesso em: 01 março 2021.

RODOVIÁRIA DO RIO. Dados sobre a movimentação de passageiros em 2019 e 2020. 2020. Mensagem recebida por imprensa@rodoviariadorio.com.brem 17 de agosto de 2020.

SOARES, Luís Augusto Severo. Turismo e trabalho informal: um binômio inevitável? Revista Gerenciais, São Paulo, v. 4, p. 89-98. 2005.

SILVA, Heitor Ney Matias da. A crise do estado do Rio de Janeiro, relações econômicas e políticas. Rio de Janeiro. Boletim Conjuntura, Boa Vista, v. II, n. 4. 2018. Disponível em: https://repositorio.ufsc.br/bitstream/handle/123456789/182555/Conflitos-eRevolucoes-29-41.pdf?sequence=1\&isAllowed=y

WTTC. World Travel \& Tourism Council.Relatórios de impacto econômico. 2014. Disponível em https://wttc.org/Research/EconomicImpact Acesso em: 22 fevereiro 2020.

WTTC. World Travel \& Tourism Council. Relatório de impacto econômico das cidades. 2019. Disponível em https://wttc.org/Research/Economic-Impact/Cities Acesso em: 22 fevereiro 2020. 